\title{
Arte urbano, entre la mercantilización y la resistencia El caso de La Boca (Buenos Aires)
}

\author{
Universidad de Buenos Aires, Instituto de Ciencias Antropológicas, Facultad de Filosofía y Letras, Buenos \\ Aires, Argentina \\ Consejo Nacional de Investigaciones Científicas y Técnicas, Buenos Aires, Argentina \\ ORCID iD: 0000-0001-9583-3184 \\ Correo electrónico: mercedesbracco@yahoo.com.ar
}

Recibido

enero de 2019

Aceptado

julio de 2019

\section{Resumen}

En la actualidad, el Gobierno de la Ciudad de Buenos Aires ha avanzado sobre los espacios relegados del sur de la ciudad con políticas de embellecimiento del espacio público y desarrollo inmobiliario. En La Boca, la creación del "Distrito de las Artes" busca capitalizar la tradición barrial de artistas plásticos para traccionar negocios a partir de la implantación de murales y actividades culturales. Frente a esto, algunas organizaciones sociales impulsaron una oposición con las mismas herramientas que el gobierno usa para atraer turistas e inversores. Mediante un trabajo etnográfico que incluye observaciones de campo, recorridos turísticos y entrevistas, se indaga en las nuevas formas que adopta la resistencia popular a los avances mercantilizadores del gobierno y los desarrolladores privados.

\section{Street art, between commodification and resistance. The case of La Boca (Buenos Aires)}

\begin{abstract}
At present, the Buenos Aires City Government has made headway on neglected spaces in the south of the city with policies for public space embellishment and real estate development. In La Boca, the establishment of the "Arts District" seeks to capitalize on the neighborhood's visual arts tradition to traction businesses through introduction of murals and cultural activities. Facing this situation, a number of social organizations initiated an opposition utilizing the same tools as the Government uses to attract tourists and investors. Through ethnographic work, including field observations, sightseeing tours and interviews, this article looks into the new forms taken by the popular resistance to Government and private developers' commodification advances.
\end{abstract}

\section{Palabras clave}

Arte urbano; Mercantilización; Turismo; Organizaciones vecinales; Buenos Aires

\section{Key words}

Street art; Commodification; Tourism; Neighborhood associations; Buenos Aires 
Palavras-chave

Arte urbana; Mercantilizaçao; Turismo; Organizações da vizinhança; Buenos Aires

1. Tomo esta expresión de Murillo (2013).

\section{Arte urbana, entre a mercantilização e a resistência. $O$ caso de La Boca (Buenos Aires)}

\section{Resumo}

Atualmente, o Governo da Cidade de Buenos Aires tem avançado sobre os espaços confinados do sul da cidade com políticas de embelezamento do espaço público e desenvolvimento imobiliário. No bairro de "La Boca", a criação do "Distrito de las Artes" procura capitalizar a tradição da vizinhança dos artistas plásticos para movimentar os estabelecimentos comerciais a partir da implantação de murais e atividades culturais. De cara a esta situação, algumas organizações sociais se opuseram a este movimento com as mesmas ferramentas que o governo utiliza para atrair turistas e investidores. Através de um trabalho etnográfico que inclui observações de campo, passeios turísticos e entrevistas, são investigadas as novas formas adotadas pela resistência popular aos avanços mercantilizadores do governo e dos investidores privados.

\section{Introducción. Buenos Aires, distritos económicos para la "ciudad- empresa"1}

A pesar de las marcadas diferencias entre centro y periferia, una mirada actual sobre las ciudades globales permite verificar estrategias y modos de gestión que resultan similares en muchos aspectos. Las necesidades del capital financiero, la velocidad de la comunicación y los avances de la tecnología dan como resultado un paisaje urbano en muchos aspectos comodificado, que busca mostrarse abierto tanto a negocios inmobiliarios como al turismo internacional. Se trata de una reconversión de la ciudad de acuerdo con la cual la belleza y la seguridad se transforman en imperativos para gestionar lo urbano, en que los problemas sociales se disuelven en problemas estéticos y las políticas de embellecimiento reemplazan a las políticas urbanas en su conjunto (Amendola, 2000).

En este contexto, en los últimos 25 años la Ciudad de Buenos Aires viene experimentando una serie de cambios en materia de política urbana mediante los cuales las sucesivas administraciones locales buscaron maximizar la renta del suelo y fomentar los espacios de consumo para turistas y vecinos de clases acomodadas en detrimento de la inclusión de sectores vulnerables. Al día de hoy contamos con una abundante literatura dedicada al estudio de las diversas caras que adopta este modo de gestionar lo urbano: desde la renovación del frente portuario (Novoa, 2005), pasando por la explosión inmobiliaria (Szajnberg, 2010), la recualificación/gentrificación de barrios y áreas de la ciudad (Mignaqui, Szajnberg y Ciccolella, 2005; Carman, 2006; Thomasz, 2012; Hernández, 2017) y la gestión del patrimonio arquitectónico y cultural de cara al turismo (Gómez Schettini y Zunino Singh, 2008; Zarlenga y Marcús, 2014).

Con este horizonte, bajo la gestión de Mauricio Macri y Horacio Rodríguez Larreta iniciada a fines de 2007, el Gobierno de la Ciudad de Buenos Aires (GCBA) ha avanzado sobre las áreas relegadas del sur de la ciudad con políticas vinculadas al embellecimiento del espacio público, el incremento de la seguridad y el desarrollo de nuevas movilidades. Esto se suma la mudanza de oficinas de gobierno del centro de la ciudad a edificios de alto impacto en el sur. 


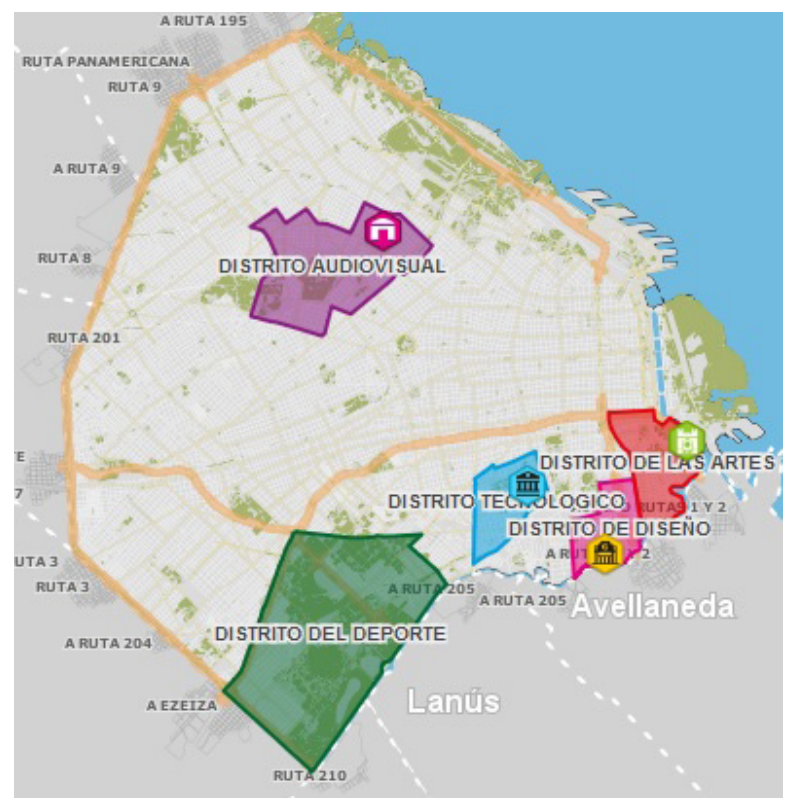

Figura 1. Distritos de la ciudad de Buenos Aires.

Fuente: https://www.buenosaires. gob.ar/distritoseconomicos/ mapadistritos (fecha de consulta 10/02/17)
Dichos desplazamientos operan como punta de lanza en pos de atraer proyectos de desarrollo inmobiliario amparados en la conformación de clusters creativos o industriales denominados "distritos" (Figura 1). Según indica Socoloff (2013), la creación de distritos responde a la necesidad de intervenir un perímetro amplio - en contraposición a la idea anterior de "polo" según la cual la intervención se limitaba a un solo predio- donde el Estado opera como facilitador de los negocios privados a partir de beneficios impositivos que fomentan el "desarrollo económico" de la zona al tiempo que la "revitalizan", a fin de revertir su "deterioro" e "inseguridad".

La política de distritos se desplegó mayoritariamente en el sur de la ciudad, tradicionalmente considerado como "atrasado", 2 con excepción del Distrito Audiovisual único ubicado en su sector norte- que fue delimitado en un área donde ya se encontraban asentadas muchas productoras de cine y televisión, estudios, canales y empresas asociadas, lo que consolidó una tendencia anterior. Dentro de los que se encuentran en la zona sur, los casos son diversos. El Distrito de Diseño y el Distrito Tecnológico son una invención del gobierno que busca atraer empresas creativas vinculadas al diseño y la tecnología a antiguas zonas fabriles con grandes capacidades edilicias subutilizadas (Goicoechea, 2017; Hernández, 2017). El Distrito del Deporte, por su parte, se vincula con el desarrollo de las Olimpiadas de la Juventud 2018, megaevento que fue aprovechado por el gobierno para llevar adelante un gran emprendimiento inmobiliario en el barrio de Villa Soldati, uno de los más pobres de la ciudad, donde la renta del suelo es comparativamente baja. ${ }^{3}$

También en la zona sur se ubica La Boca, barrio popular y cuna de famosos artistas plásticos, que durante muchos años estuvo marginado de las políticas públicas y cuenta con una importante red de organizaciones barriales (culturales, sociales y/o políticas) históricamente muy activas. La conformación del Distrito de las Artes en dicho sector busca capitalizar su importante tradición artística para traccionar negocios urbanos que estimulen al turismo cultural y residencial a partir del emplazamiento de murales y la realización de actividades culturales que iluminan nuevas zonas del barrio (Fabarón, 2013; Thomasz, 2017).

Es sobre este caso que, a partir de un estudio etnográfico que incluye observaciones de campo, recorridos turísticos y entrevistas a los actores involucrados, el presente trabajo busca mostrar, por un lado, las formas materiales y discursivas que desarrolla
2. Los orígenes de esta percepción pueden rastrearse en los distintos tiempos que tuvo la modernización en la ciudad, irradiada de manera desigual desde el centro hacia los barrios. El asentamiento de los sectores acomodados en la zona norte a fines del siglo xIx y el avance residencial informal y dispar sobre el resto de la grilla urbana repercutieron en las formas y tiempos de dicha modernización. Como ejemplo temprano de la intención de equilibrar esta desigualdad se encuentra el desarrollo de viviendas obreras llevadas adelante por la Iglesia, los sectores socialistas y el propio municipio en el sur de la ciudad durante principios del siglo xx y la creación del Parque de los Patricios, en 1902, con una infraestructura similar a la de los bosques de Palermo para el disfrute de los sectores obreros, denominado por ello el "Palermo de los pobres" (Gorelik, 2004; Gutman y Hardoy, 2007).

3. Este desarrollo incorporó elementos que ya venían estudiándose en torno a un "Plan Maestro" para la Comuna 8 (que incluye los barrios de Villa Soldati, Villa Lugano y Villa Riachuelo), que pudieron avanzar luego de la votación de la ley del Distrito del Deporte en 2014. Al respecto, véase Roitman (2017). 
el GCBA para reposicionar este sector; por el otro, las innovadoras estrategias que adopta la resistencia popular a estas acciones. El estudio se inicia con una descripción sobre el desarrollo del grafiti, el muralismo y otras expresiones de arte público en la Cudad de Buenos Aires. Luego se explica brevemente la historia sociocultural de La Boca, atendiendo al impacto del Distrito de las Artes en el territorio. A continuación, se detalla el programa de arte público del GCBA que más impacto ha tenido en los últimos años y las acciones artístico-culturales ideadas por los vecinos para contraponerse a aquellas llevadas adelante por el gobierno. Finalmente, se exponen algunas reflexiones sobre esta dinámica.

\section{El auge del street art o la mercantilización del vandalismo}

En varios de sus trabajos, Schacter $(2014,2016)$ relata la forma en que el grafiti, expresión plástica hasta hace poco clandestina y vandálica, ha travestido en arte urbano y ha tomado las calles de las principales ciudades del mundo de la mano de promotores privados, gobiernos, referentes y críticos de arte. Este investigador inglés ha mostrado cómo, si durante sus primeras décadas de vida entre los grafiteros prevalecía el valor de la autonomía, el espacio público como soporte y una performatividad vinculada a la osadía de la acción ilegal, en la actualidad mucho de esto se ha subvertido. En oposición al espíritu de sus comienzos, en los últimos años, los festivales de arte público han fagocitado la otrora práctica clandestina para ponerla al servicio del poder económico y político que se sirve de él para posicionar barrios o sectores de distintas ciudades como disponibles y apetecibles para el mercado inmobiliario.

En tal sentido, el desarrollo de la idea de "ciudad creativa" responde a los intereses de reincorporar y valorizar espacios antes considerados degradados o en desuso. Allí, el arte urbano transforma el espacio público en un bien mercantil mediante los festivales de arte como eventos pasteurizados donde lo que antes se consideraba vandalismo es relanzado positivamente por sus valores de autenticidad, libertad y singularidad.

Dentro de este contexto global, el caso de Buenos Aires replica algunas de estas características pero también muestra sus particularidades. La ciudad cuenta con una tradición de arte y muralismo político que se remonta a las primeras décadas del siglo xx, sobre todo a partir de la visita del mexicano Alfredo Siqueiros (Belej, 2014). Además, las paredes siempre fueron espacio de confrontación y lucha entre partidos políticos, que pintan sus consignas mientras tapan las pintadas de los rivales.

Más cerca en el tiempo, el grafiti aparece localmente asociado a subculturas jóvenes. Junto con los escritos personales ("Marta te quiero") y de apoyo a alguna pasión ("River Campeón"), gran parte de los grafitis encontrados en la vía pública durante la década del ochenta consistían en frases que, de manera lúdica e irónica, buscaban incomodar con su mensaje (Kozak, 2004). A partir de los años noventa, con la apertura de las importaciones y las comunicaciones globalizadas, el grafiti se fue complejizando, y dio lugar a otros más visuales. Si bien hubo algunos que continuaron con los mensajes sociales y políticos, muchos de ellos simplemente buscaban marcar territorio (tagging) en un juego cerrado - que ya no interpelaba al peatón, sino que requería de cierto conocimiento del código utilizado - en vinculación con nuevos formatos y técnicas que se expandieron gracias a la posibilidad de estos jóvenes de viajar al exterior y el furor internacional por el hip hop, música asociada a esta práctica.

Por otro lado, para comprender el florecimiento local de esta expresión hay que detenerse en ciertos rasgos idiosincráticos de la Ciudad de Buenos Aires. Como explica Kozak (2004), una singularidad de la capital argentina es la alta tolerancia a los ilegalismos, lo que hace que tradicionalmente el grafiti haya podido expandirse con mayor 
o menor preeminencia pero de manera ubicua en la ciudad y alrededores. No obstante, el verdadero despegue local aparece ya con el mote de 'arte urbano' luego de la crisis económica e institucional de 2001, pues en ese momento se revaloriza la idea de tomar la calle. Este contexto generó una multiplicidad de colectivos que no solo pintaban (en) la calle, sino que hacían intervenciones urbanas de distinto tipo destinadas a reflejar la crisis en la que estaba inmerso el país. De ese momento convulsionado surge también la consigna de pintar las paredes como forma de resistencia a las imágenes publicitarias que inundaban la ciudad, ajenas a la pauperización de su población. Sin embargo, durante el proceso de recuperación económica, este movimiento fue rápidamente cooptado por el mercado. Como resultado, muchos colectivos terminaron disgregándose y aparecieron con más fuerza las individualidades:

Con DOMA de alguna forma arrancamos, hicimos toda una carrera y pasó esto que obviamente en esa época del 2001, la crisis, explotaron los colectivos, así como nació DOMA nacieron un montón [...]. La realidad es que eso pasó en la crisis, nos juntamos todos, después apareció Fotolog, Facebook, Instagram, las redes, y ahí surgió la individualidad al mango y se empezaron a romper todos los colectivos, o sea, quedaron muy pocos. (Artista urbano, entrevista personal, noviembre de 2017)

Esto coincide con un cambio en las formas de emplazamiento del marketing global, según el cual las ciudades-marca deben hacer cada vez más esfuerzos para mostrarse en un mercado fuertemente disputado. A comienzos del nuevo milenio, Buenos Aires contaba con la ventaja de un tipo de cambio muy favorable y un mercado inmobiliario deprimido luego de la crisis, lo que redundó en un periodo de florecimiento para el turismo y las inversiones internacionales. En este contexto, el GCBA comenzó a coordinar acciones vinculadas al arte urbano, la gastronomía y el turismo en colaboración con artistas, emprendedores y empresas privadas. Así, a los festivales internacionales de cine, teatro y tango, la ciudad sumó nuevos eventos para la promoción de ferias gastronómicas, festivales de "artistas emergentes" y nuevos circuitos turísticos. El foco puesto en el arte urbano tenía que ver con su visibilidad e impacto y, si bien los primeros encuentros tuvieron lugar en barrios de clase media como Palermo, Villa Crespo y Coghlan — que ya venían siendo intervenidos espontáneamente por los artistas-, el gobierno incorporó otras zonas turísticas al sur de la ciudad, como San Telmo y La Boca, como parte de una política de intervención más amplia.

Cabe aclarar que el auspicio de estos encuentros también funciona como forma de ordenar y disciplinar el espacio público pues, al mismo tiempo que fomenta la intervención de las paredes en ciertos ámbitos controlados, el GCBA cuenta con una "brigada antigrafiti" que "limpia" las paredes de la ciudad. La prensa regularmente da noticias acerca del costo de estas limpiezas y también celebra las detenciones realizadas por la policía a jóvenes que pintan grafiti sobre los coches del subterráneo.

Queda así determinada la diferencia entre lo que es considerado como arte urbano - aquel que es fomentado por el gobierno y las empresas, que cuenta con promotores económicos y se organiza en encuentros internacionales cuidadosamente curados y difundidos - y aquello que es acusado de vandalismo - ilegal, efímero, clandestino, popular y siempre amenazado por/amenazante para el poder público-. En este contexto, junto con grafitis y pintadas políticas, muchos murales con mensaje social o político fueron y siguen siendo tapados o "limpiados" en toda la ciudad. Es a partir de estas diferencias que se puede comprender cómo el arte urbano está siendo utilizado como herramienta de disciplinamiento en La Boca, un barrio con una importante tradición artística que no condice con la actualmente promovida por gobierno.

\section{La Boca ayer y hoy: cambios y permanencias, amenazas y oportu-}


4. Si bien en el imaginario prevalece la "italianidad" asociada a la historia de La Boca, esta operación invisibiliza otros aportes migratorios tempranos, como los paraguayos, uruguayos y población proveniente del interior del país, lo que contribuye a la legitimación de ciertos habitantes por sobre otros. Al respecto, véase Lacarrieu (1993).

5. Referente y "héroe" del barrio, el pintor Benito Quinquela Martín (1890-1977) fue un huérfano adoptado por una humilde familia italiana residente en La Boca. De padre carbonero, muy tempranamente comenzó a dibujar y pintar

la cotidianeidad de su barrio, y logró reconocimiento a nivel nacional e internacional. Ya famoso, destinó parte de su fortuna a la compra de inmuebles para el establecimiento de instituciones

necesarias para el barrio: una escuela, un jardín de infantes, un lactario, un hospital odontológico y un teatro. Para un mayor detalle de su vida y obra véase Muñoz (1966).

6. Sobre el proyecto RECUPBoca y otras políticas habitacionales en La Boca, véase Lacarrieu (1993) y Guevara (2011).

7. La camiseta tradicional del equipo es azul con una franja horizontal amarilla.

\section{nidades}

La historiografía urbana de Buenos Aires muestra a La Boca como un espacio singular desde sus inicios. A pesar de encontrarse geográficamente cerca del centro cívico y comercial de la ciudad, en términos simbólicos siempre se consideró como un lugar alejado y con características propias. La literatura sobre este barrio hace hincapié en su origen inmigrante, marcado por una fuerte impronta italiana - particularmente genovesa $-{ }^{4}$ y su original arquitectura, conformada por una gran cantidad de conventillos de chapa y madera construidos en altura para resistir las frecuentes inundaciones, producto del desborde del Riachuelo. A pesar de su precariedad, el funcionamiento del puerto le dio a este barrio una vida económica y social muy activa, con asociaciones de diverso tipo. Con fuerte peso en lo cultural, entre ellas se destacaron las asociaciones de artistas plásticos, con Benito Quinquela Martín ${ }^{5}$ como principal referente.

La imagen urbana de esta área de la ciudad fue muy tempranamente presentada en términos positivos. A los famosos cuadros de Quinquela que muestran orgullosamente el trabajo portuario se sumaban fotografías de espacios icónicos como la Vuelta de Rocha, el Puente Transbordador Nicolás Avellaneda y las cantinas italianas en guías de la ciudad y en los diarios más reconocidos. A partir de 1959, a la iconografía barrial se le sumó otro punto emblemático: Caminito. Esta callecita cortada que había quedado abandonada luego de que un ramal del ferrocarril que por allí pasaba dejara de funcionar, fue revitalizada por un grupo de vecinos notables encabezados por Quinquela, quienes la transformaron, por medio del color, en un espacio escenográfico dispuesto como "Museo de Arte al aire libre" (Muñoz, 1966, p. 204).

La inauguración de Caminito comenzó a atraer, si bien en pequeña escala, al turismo local, nacional e internacional al barrio a partir de la década del sesenta. A pesar de que este punto siempre permaneció iluminado en los circuitos turísticos, durante los años setenta, la desactivación definitiva del puerto dio inicio a un proceso de cambios económicos y sociales que acompañaron al fuerte deterioro urbano sufrido desde entonces. La mirada sobre La Boca se volvió entonces negativa, con énfasis en su abandono y degradación. Recién en los años noventa el gobierno dio solución a las inundaciones, y un proyecto de rehabilitación de algunos conventillos iniciado años antes fue reconfigurado de modo que ya no fueron destinados a vivienda sino a emprendimientos comerciales y/o culturales, lo que reforzó aún más el perfil escenográfico for export de esta zona. ${ }^{6}$ Además, esa pequeña porción de conventillos de chapa y madera pintados profusamente de colores fuertes que se muestran sobre Caminito como parte de la singularidad pintoresquista del barrio oculta la realidad de la mayoría de este tipo de inquilinatos: la precariedad de su construcción, la deficiencia de sus servicios públicos e infraestructura, el hacinamiento de sus habitantes, la arbitrariedad de los alquileres informales, los desalojos y los incendios frecuentes que amenazan a las numerosas familias que allí residen, en su mayoría de escasos recursos.

En la década del noventa se sumaron dos cambios importantes que influyeron en las percepciones sobre el barrio. El primero fue la llegada del museo privado de arte contemporáneo PROA, que, instalado en un antiguo inmueble remodelado en uno los vértices de Caminito, trastocó la tradición estética de la zona y comenzó a atraer nuevos públicos no interesados en las otras propuestas culturales del barrio. El segundo fue la llegada de Mauricio Macri a la presidencia del club Boca Juniors, cuya gestión lo sacó de la bancarrota para transformarlo en un negocio internacional que dejó afuera a los vecinos. La contracara de esta expulsión resultó en una estetización del club, que se transformó en otro de los atractivos turísticos del barrio. Como observa Fabarón (2013), a la "trama multicolor" quinqueliana se suma así la "trama azul y oro"7 expandida en los colores con que fue pintado el estadio, los murales alusivos en sus paredes 
exteriores, el "Museo de la Pasión Boquense" que hoy opera con gran impacto en los visitantes internacionales y los negocios de souvenirs ubicados alrededor del estadio.

Este proceso forma parte de un contexto de transformación más profundo, que propone una nueva percepción del barrio. Aquí coincidimos en la observación que propone Ana Gretel Thomasz (2017) sobre los cambios físicos y simbólicos a partir del establecimiento del Distrito de las Artes en 2012. Hasta entonces, relata la autora, el imaginario vinculado a La Boca se encontraba traccionado por dos representaciones predominantes: una positiva, ligada a la tradición, que alimentaba la imagen turística de conventillos coloridos como escenario de artistas plásticos callejeros y parejas bailando tango; y otra negativa, que asocia la degradación urbana del barrio a una degradación social plagada de crímenes, basura y marginalidad. A partir de la creación del Distrito de las Artes (Ley No 4353/12), que promueve mediante incentivos fiscales la radicación de emprendimientos comerciales e inmobiliarios que incorporen propuestas artísticas, nuevos imaginarios vinculados a la innovación, el desarrollo y la cultura comenzaron a disputar los sentidos hegemónicos anteriores. ${ }^{8}$

Enfocados en una idea de promoción de los negocios inmobiliarios en vinculación con el arte, diversos proyectos urbanos comenzaron a ser desarrollados sinérgicamente por los ministerios de Espacio Público, Cultura y Desarrollo Económico. En términos de cambios físicos, las transformaciones en el barrio se proyectan en torno a la construcción de torres de vivienda para sectores acomodados y nuevos paseos turísticos. A esto se suma la renovación del Paseo de la Ribera que bordea la boca del Riachuelo y el avance del "Metrobus del Bajo", que conectará el centro de la ciudad con La Boca; la remoción de asentamientos informales en las áreas del bajoautopista para conectar el exclusivo barrio de Puerto Madero con La Boca y el desalojo de muchos conventillos que ya están siendo demolidos para el desarrollo de nuevos proyectos inmobiliarios de tipo comercial o residencial (Figura 2).

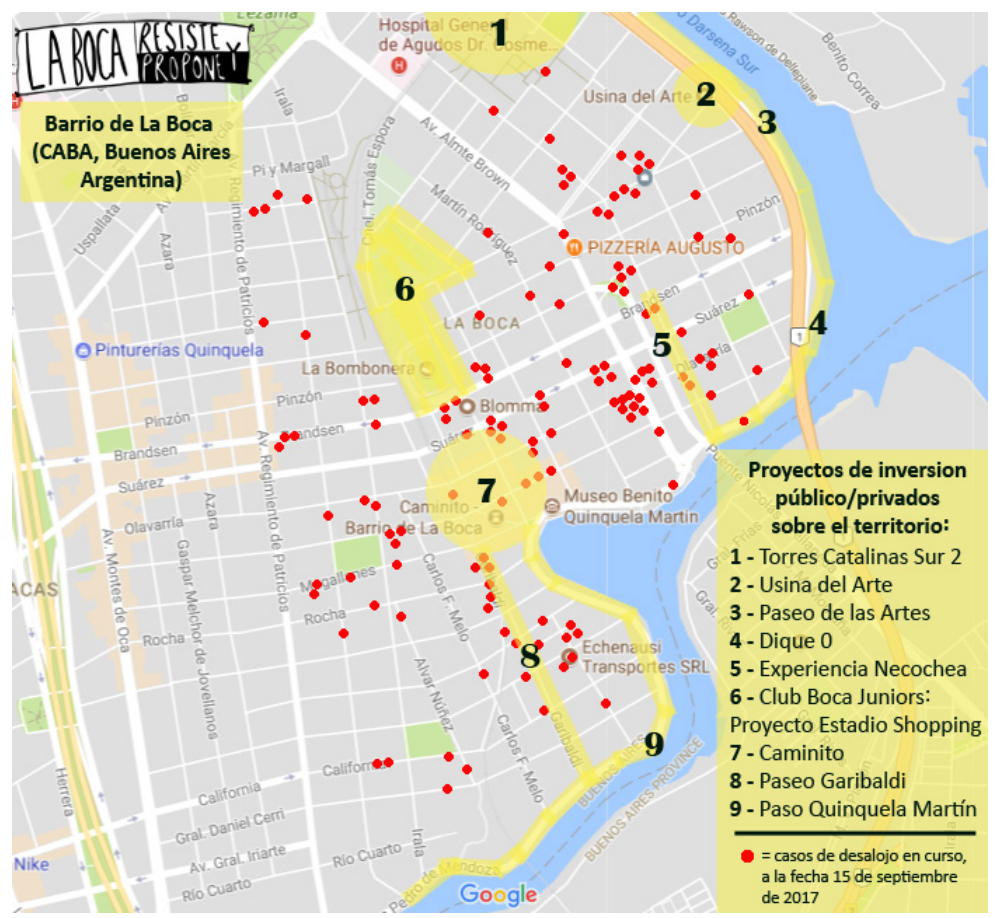

8. Es interesante observar que la posibilidad de que el desarrollo del Distrito de las Artes implicara el encarecimiento del costo de vida para los vecinos del barrio se encontraba contemplada desde un inicio en la misma letra de la ley, que en su artículo 29 indica: "El Poder Ejecutivo, a través del órgano que corresponda, atenderá la situación de vulnerabilidad social en la zona, relevando la necesidad de soluciones habitacionales y dispondrá acciones direccionadas a facilitar la permanencia de las familias radicadas actualmente en el Distrito de las Artes". Hasta el momento, este punto no se ha cumplido.
Figura 2. Mapa que vincula los desalojos con los grandes proyectos urbanos en el barrio de La Boca.

Fuente: La Boca Resiste y Propone, septiembre 2017. 
9. Murillo (2013) define los "espacios abyectos" como "lugares habitados por cuerpos carentes de voz, ignorados, denegados; esos espacios se caracterizan porque en ellos la ley puede ser suspendida y la violencia ejercida en silencio; son lugares en los que la existencia humana queda en suspenso, zonas sólo pobladas por fantasmas, por figuras invisibles para los ojos del "nosotros'” (p. 33).
Llegado este punto, es necesario aclarar que no todo el barrio es percibido de la misma manera, ni por los visitantes ni por los residentes. Para el caso de los primeros, la espacialidad y temporalidad de las visitas están dadas por los horarios y localización de los comercios y museos, junto con las advertencias por parte de guías, policías y vecinos de que no se alejen de la zona turística porque puede ser peligroso (González Bracco y Kotschack, 2017). Respecto de los vecinos, en varias entrevistas se revelan divisiones que establecen subbarrios a los que solo acceden los locales. Las zonas de Catalinas, el Bajo y el Barrio Chino son las más mencionadas, y quienes no son de allí no suelen transitarlas, ya sea por peligro, por desconfianza, o simplemente porque se sienten foráneos.

Estas divisiones al interior del barrio también marcan fronteras y prácticas espaciales que habilitan o limitan el desarrollo de los emprendimientos llevados a cabo por el GCBA. En este sentido, se observa un esfuerzo explícito por ampliar el circuito turístico en forma de derrame y así conectar la zona lindera a los turísticos barrios de San Telmo y Puerto Madero con el ya consolidado circuito de Caminito. Esta área, aledaña a la Usina del Arte, está rodeada de galpones y empresas pero, al mismo tiempo, está muy cerca del complejo de edificios de Catalinas Sur, que es, al decir de un vecino, "lo más burgués, clase media" que tiene el barrio (vecino y gestor cultural de La Boca, entrevista personal, enero de 2018). Por el contrario, la zona del Barrio Chino, que puede entenderse en términos de "espacio abyecto" dentro de La Boca, continúa siendo vedada para personas ajenas a ese perímetro y aún no resulta atractiva a las inversiones inmobiliarias (Figura 3).

Es así como, en un juego de palabras planteado por una entrevistada, se configuran dos proyectos irreconciliables que utilizan el arte como herramienta central. Uno, el
Figura 3. Zonas al interior de La

Fuente: Elaboración propia. sobre mapa del GCBA.

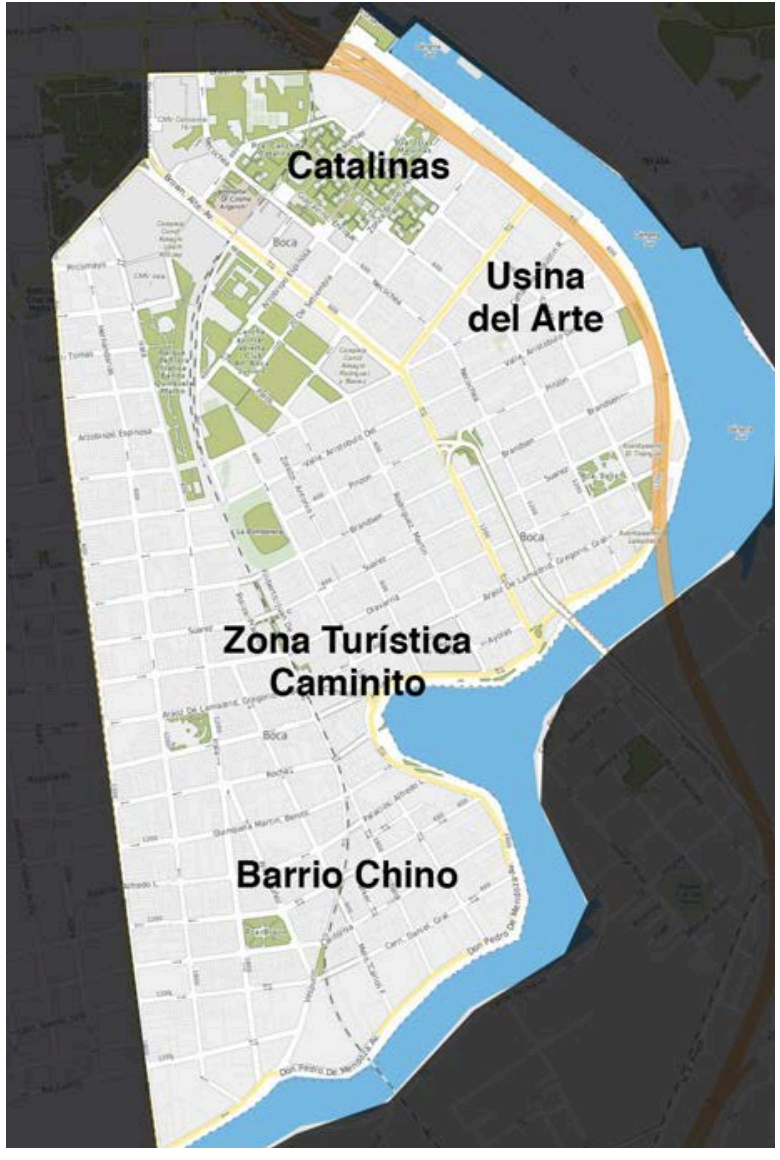


del gobierno, se arma "de la boca para afuera" (artista plástica y vecina de La Boca, entrevista personal, agosto de 2017): aquí el arte concilia la historia romantizada del barrio con un presente dinámico y lleno de oportunidades para el ocio y el consumo, por lo que es pensado para "usuarios solventes" (Thomasz, 2012) tales como inversores, visitantes y turistas. El otro, el de los vecinos, es construido "de la boca para adentro" (artista plástica y vecina de La Boca, entrevista personal, agosto de 2017): aquí el arte sirve para denunciar y resistir al proyecto gubernamental de exclusión, busca rescatar la historia y la actualidad del barrio y plantea redes de solidaridad con los afectados por estas políticas.

\section{De la boca para afuera: Color BA o Wynwood en La Boca}

A partir de la puesta en funcionamiento la Usina del Arte, en 2012, el GCBA comenzó a desarrollar en torno a ella nuevos circuitos turísticos, eventos y festivales destinados a un público joven. Al mismo tiempo, nuevas galerías y espacios de arte privados comenzaron a establecerse en el barrio. La presentación de esta "nueva" cultura incluye al arte urbano, que comienza a cobrar interés como parte de la moderna percepción sobre La Boca. La aparición de Color BA, un programa específico de arte urbano perteneciente al Ministerio de Espacio Público que, hasta la fecha, tuvo cuatro ediciones en La Boca (septiembre de 2016, marzo de 2017, septiembre de 2017 y septiembre de 2018), ${ }^{10}$ es presentado por sus promotores como una forma de sumarse a tendencias internacionales, en colaboración con muralistas reconocidos y con eventos culturales ya instalados en la agenda de la ciudad que abran nuevas áreas del barrio al conocimiento de vecinos y turistas y ayude a cambiar la percepción sobre dichos espacios:

En realidad no hicimos nada novedoso, sino que seguimos una tendencia que empezaba a aparecer en otros lugares. [...] Yo creo que lo que diferencia lo que empezamos a hacer nosotros es la magnitud, porque arte urbano había, había artistas que pintaban, que hacían pequeños festivales o cosas pero nosotros teniendo la oportunidad desde Gobierno de hacerlo y que parecía interesante poder invertir en eso. $\mathrm{O}$ sea, la realidad es que cuando uno tiene una pared blanca o gris no es lo mismo que tener una obra que está buenísima. Tratamos de hacer como, revitalizar zonas a partir del arte, o sea, esa es la premisa. [...] Por ejemplo, en La Boca - que es como el centro de todo lo que fue Color BA hasta ahora y que vamos a seguir trabajando en esa zona-, cambió la apropiación de las paredes, el cuidado de las paredes, la gente sale a recorrer, se generan unos circuitos de recorrido, cosa que antes, o sea, vos ibas a La Boca e ibas a la Usina, pero te quedaba tal vez aislada, hay algunas galerías que están medio desconectadas y ahora tenés un recorrido de murales en donde vas de una galería a otra en el medio viendo murales, entonces como que ya el recorrido en sí se genera más atractivo y ya de por sí genera otro impacto visual. (Coordinadora de Color BA, entrevista personal, enero de 2018)

La mirada que plantea esta funcionaria sobre el arte tiene que ver con su uso como parte de un entramado revitalizador en torno a la Usina, área del barrio a la que se le quiere dar esta nueva impronta complementada por festivales y nuevos circuitos turísticos. Dentro de esta perspectiva, sin embargo, no se retoma la tradición boquense en las artes plásticas, por considerarla, por un lado, demasiado folklórica, cuando lo que se quiere mostrar es un arte contemporáneo y novedoso; y por el otro, demasiado politizada, frente a la intención de presentar una imagen más liviana y atractiva:

Lo que nosotros queríamos era generar una especie de polo más moderno de muralismo dentro de La Boca separado de lo que es el circuito de murales y el circuito de arte de Caminito, porque nos parecía que la estética, a ver, si yo quería replicar un Caminito hubiese ido a hacer un relevamiento de los artistas barriales y
10. La edición de 2018 se hizo en el contexto del festival internacional Art Basel y se extendió por varios barrios turísticos (La Boca, Puerto Madero y Palermo). Asimismo, en 2018 el programa también tuvo otra edición en asociación con el colectivo "Proyecto Persiana" para pintar murales en persianas de comercios en distintos puntos del centro porteño. 
11. El GCBA ha realizado diversos registros audiovisuales de los murales que pueden verse en YouTube. A modo de ejemplo: https://www.youtube. com/watch?v=zjIP7NuBwzA, https://www.youtube.com/ watch?v=1XmGpLkmErg los llevaba a la Usina del Arte. Yo lo que quería era generar un movimiento distinto en la Usina, o sea, alrededor. Quería que sea una estética de festival internacional donde no haya ningún tipo de cuestionamiento o de cosa social o de derecho ni de reivindicaciones ni de nada de nada. La mayoría de los artistas barriales de La Boca son asociaciones que hacen murales sobre cuestiones de género, aborto, trabajadores. O sea, me parece fantástico, pero acá para la primera edición no queríamos que se mezcle eso. Sentíamos que no íbamos a generar ningún tipo de impacto diferente si volvíamos a hacer lo mismo que se había hecho en Caminito. (Productora de ColorBA, entrevista personal, octubre de 2017)

Como se desprende de los relatos, el hecho de haber dejado afuera a los artistas históricos del barrio fue algo buscado por el programa en un intento de generar novedad y despolitizar lo que dicen las paredes. Al respecto, la coordinadora entrevistada comentaba que una de las críticas que recibieron fue precisamente que algunos de los murales eran "muy livianos" en cuanto a su contenido. La productora agregaba que, en algunos casos, si bien a los vecinos les gustaban los murales, "no los entendían", lo que deja en evidencia que no respondían a la tradición mural del barrio. Respecto de la temática a pintar, las entrevistadas mencionaron que no hubo censura de ningún tipo, aunque sí se pidió que no fueran temas políticos o controvertidos. ${ }^{11}$ Esto resulta interesante al contraponerlo con el hecho de que, como se menciona en el apartado anterior, muchos artistas urbanos locales surgieron pintando murales con algún mensaje político. Entonces, para lograr que la participación fuera importante y que el patrocinio del GCBA no resultara problemático, hubo que matizarlo:

la marca Color BA, si te fijas, está super alejada de la imagen de Gobierno, o sea, es un logo que no tiene ningún tipo de referencia al Gobierno de la Ciudad [...] Pero queríamos que fuese una cosa más, que sea apolítico, como que sea lo más fuerte posible y poder tener artistas que no nos cuestionen en ese sentido [...] porque los artistas en general tienen sus limitaciones en cuanto a eso y no queremos que eso pase, o sea, perdernos un buen artista por tener alguna imagen política sería una pena (Coordinadora de Color BA, entrevista personal, enero de 2018).

Ahora bien, ¿cuál es el destinatario imaginado de esta política despolitizada? Los funcionarios del GCBA mencionan tanto a los vecinos de la ciudad como a los turistas y la necesidad de que se "reapropien" de este espacio, que ya no lo consideren peligroso ni anónimo sino con propuestas jóvenes y vibrantes. La sinergia con el festival juvenil "Ciudad Emergente" - que se realizaba desde 2007 en el Centro Cultural Recoleta y a partir de 2016 se mudó a la Usina del Arte - tiene que ver con atraer este tipo de público (Figuras $4 \mathrm{a}$ y $4 \mathrm{~b}$ ).

Una mirada sobre los circuitos turísticos actuales por el barrio también permite observar la vinculación del área turística consolidada sobre Caminito con nuevos puntos de atracción — los alrededores de la cancha de Boca Juniors y de la Usina del Arte-. El recorrido del Bus Turístico y los paseos gratuitos a pie, en bus y en bicicleta organizados por el Ente de Turismo de la Ciudad incorporan el arte urbano como refuerzo a esa apertura que, sin embargo, encuentra su límite hacia el borde sur de Caminito, donde las visitas son desaconsejadas y las inversiones en materia de infraestructura urbana y cultural son aún incipientes.

Empero, la mirada despolitizada tuvo un paréntesis obligado. Mientras que la primera, la tercera y la cuarta edición del Color BA se realizaron en confluencia con el Festival Emergente en los alrededores de la Usina, la segunda edición se realizó en los alrededores de Caminito como complemento de las acciones de mejoramiento en calzadas, iluminación y solados que el Ministerio de Espacio Público estaba llevado a cabo en el 


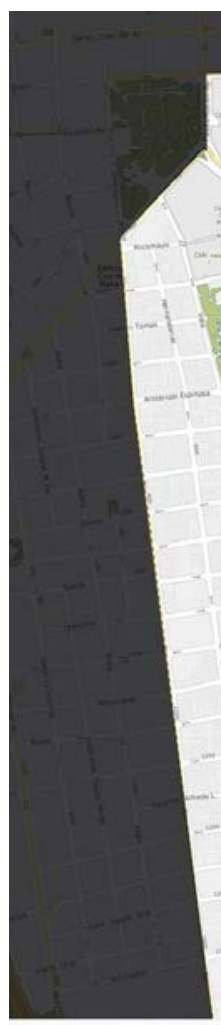

ColorBA Edición 1

ColorBA Edición 2 ColorBA Edición
Marzo de 2017

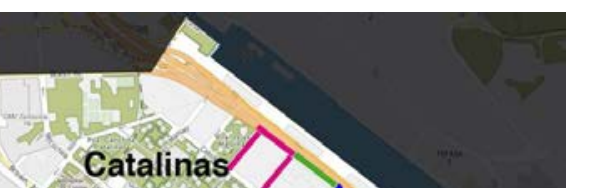

Catalinas

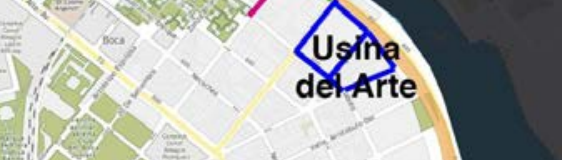

\section{Barrio Chino}

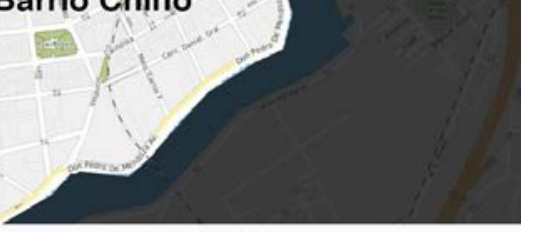

ColorBA Edición 3

ColorBA Edición 4

ColorBA Edición 4
Septiembre de 2018
Figura 4a. Ubicación de las intervenciones realizadas por el programa ColorBA.

Fuente: Elaboración propia sobre mapa del GCBA.
Figura $4 b$. Ejemplos de murales realizados por el programa Color BA.

Fuente: Instagram de Color BA.

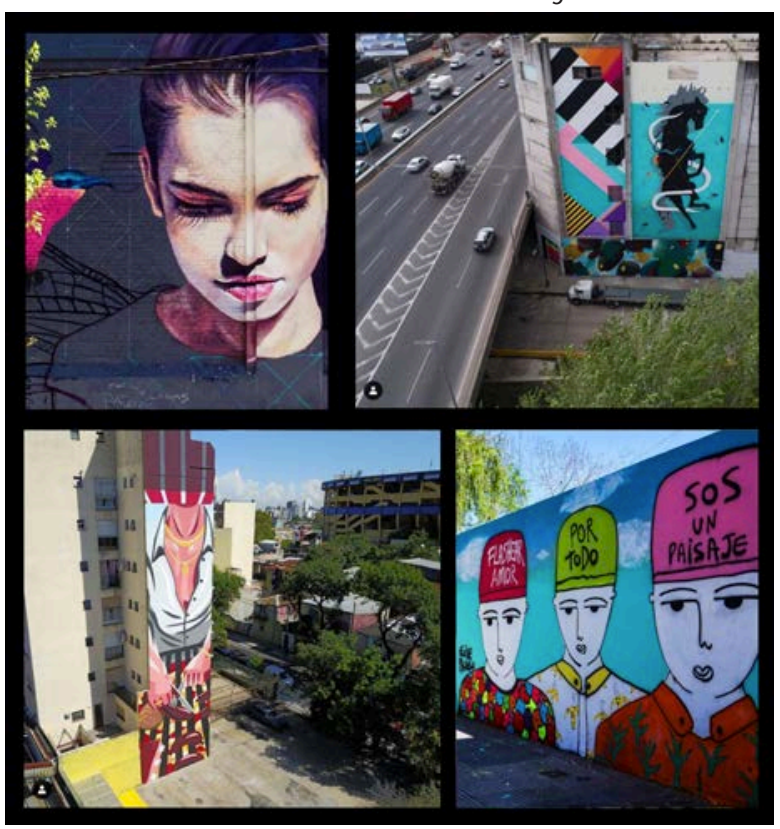

lugar, pero tuvo otra implementación debido a la necesidad de negociar con la historia y la idiosincrasia del lugar, con los vecinos y con las organizaciones barriales:

\begin{abstract}
Nosotros dijimos "Bueno, acá lo tenemos que manejar de otra manera, nosotros tenemos que sentarnos con asociaciones del barrio porque no podemos meternos", o sea, este no es un barrio, o sea, es a dieciocho cuadras de diferencia con la Usina pero son mundos completamente distintos. [...] Entonces, cuando estamos acá decimos: "Bueno, esto es otra cosa, acá estamos trabajando con vecinos que se levantan y esta es la puerta de su casa todos los días y que, no solo eso, sino que hay un montón de asociaciones que trabajan y viven La Boca de otra manera". (Productora de Color BA, entrevista personal, octubre de 2017)
\end{abstract}

Estas negociaciones fueron de diverso tipo e incluyeron desde la temática a pintar, que tenía que estar relacionada con el barrio, su historia y su gente, hasta la "protección" para cuidar los equipos utilizados en la elaboración de los murales y para moverse libremente por el barrio. En esta instancia pudo observarse al barrio apropiado por los vecinos y organizaciones, que permitieron el trabajo de la gente del gobierno pero de manera mediada con sus ideas y necesidades. No obstante, esta participación no fue avalada por todos los vecinos y organizaciones, sino que tuvo una recepción dispar. Para algunos se trataba de un reconocimiento del gobierno a los proyectos comunitarios, mientras que para otros no representaba al barrio, sino a los intereses del GCBA por atraer inversores, lo que además se complementaba con la extensa política de desalojos que se vienen llevando a cabo en el área.

Para las ediciones de septiembre de 2017 y 2018 se volvió a intervenir la zona del bajo autopista aledaña a la Usina en el contexto del festival Ciudad Emergente. Esta área era considerada vacía, peligrosa y abandonada. Buscando establecer una continuación con 
Puerto Madero mediante el proyecto del Paseo de las Artes, se incluyeron, además de los murales, otras muestras temporales de arte, eventos y foodtrucks. El área fue cercada y ya no es de libre acceso para los transeúntes. En 2017, además, el festival sumó un área verde frente a la Usina donde se realizan conciertos. Todos estos cambios permiten observar la importancia otorgada por el GCBA a la transformación del sector, lo que se complementa con otros proyectos mencionados como la extensión del Metrobus del Bajo y la renovación del Paseo de la Ribera.

\section{De la boca para adentro: arte y activismo}

A pesar de que desde el GCBA el arte urbano es presentado como algo nuevo, joven y despolitizado, ya se ha mencionado que La Boca cuenta con una importante tradición en muralismo. En tal sentido, al caminar por sus calles nos encontramos con muchas expresiones diferentes en cuanto a técnica y temática. Murales pintados, realizados con mosaicos, sobre relieves, esculturas y grafitis conviven en las calles del barrio y dan cuenta de su historia urbana - el río, los barcos, los vecinos-; sus héroes - los bomberos voluntarios-, sus pasiones - Boca Juniors- y sus muertos.

Respecto de esto último, si bien los memoriales como práctica existen desde hace varias décadas y pueden encontrarse en otros sectores de la ciudad (Kozak, 2004), en La Boca sobresalen aquellos dedicados a los muertos en los incendios y los jóvenes caídos a manos de la policía por abusos de autoridad y gatillo fácil. El "barrio peligroso" se construye así también para muchos de sus habitantes; mientras que algunos mueren a causa de las precarias condiciones de vivienda, otros son perseguidos, criminalizados y asesinados por la policía. Estas situaciones, que se dan en paralelo al "desarrollo" cultural y urbano, se han agravado en los últimos años, lo que impulsó a varias organizaciones sociales a realizar murales como estrategia de visibilización de la emergencia habitacional y de la violencia institucional sobre los jóvenes del barrio.

Por otra parte, incluso si se toman solamente en términos de espectáculo, los eventos promovidos por el gobierno no incluyen sino como huella arqueológica y romantizada a los vecinos o a los artistas tradicionales y a sus trabajos en el barrio. El festejo del Día de La Boca y la fogata de San Pedro y San Juan son algunas de las celebraciones tradicionales cooptadas y transformadas en atractivo para los visitantes y donde la participación de la comunidad funciona como escenografía:

Vos fijate aparte cómo toman esto que tiene que ver con cambiar para el nuevo destinatario, modificar el barrio para el nuevo destinatario a tal punto que toman hasta el festejo del Día de La Boca, lo monopolizaron ellos, y entonces es el Distrito de las Artes el que organiza nuestra fiesta [...] después tomó fiestas hasta religiosas, porque la fogata para cualquiera puede ser un acto cultural, para mí, que soy cristiana es una actividad religiosa, ¿me entendés? entonces, se apropian de todas nuestras representaciones, las transforman, las modifican, las hacen for export y las venden, entonces vos... la fogata, en lugar de ser en Barrio Chino, en vez de ser en el Bajo, es en Caminito, con cien gringos alrededor vendiéndole una tradición, o sea, esto, ¿iviste lo que dicen disneyficación del...? bueno, te venden la carcasa, entonces te ponen "Esto es la fogata, es la histórica fogata de La Boca nada más que ahora te traemos al arte urbano, esto y esto", que no tiene nada que ver con nosotros. (Artista plástica y referente de La Boca Resiste y Propone [LBRP], entrevista personal, agosto de 2017)

La cita es ejemplo de lo conversado con varios vecinos entrevistados, en su mayoría también artistas o gestores culturales, quienes denuncian que estas políticas del GCBA son oportunistas y que, si por un lado se apropian y "marketinizan" la identidad boquense, como contracara, ningunean, abandonan y/o destruyen el arte público que no responde 
a sus parámetros. En respuesta a esto, las acciones de varias organizaciones barriales frente a los problemas sociales y urbanos generados por la avanzada del Distrito de las Artes -desalojos, vulnerabilidad social, gatillo fácil, cerco informativo, avance de la turistificación - incluyeron también una mirada artística renovada, al entender que las estrategias de colonización del barrio por medio del arte debían ser contestadas con la misma moneda.

Esta fue la propuesta de la organización multisectorial La Boca Resiste y Propone (LBRP), que nuclea a varias agrupaciones constituidas alrededor de las diversas problemáticas del barrio, entre las que se destacan la violencia institucional hacia los jóvenes y la emergencia habitacional. Ya anteriormente al desarrollo del programa Color BA, LBRP incorporó el mural como elemento de difusión y denuncia de las situaciones que se venían dando en el barrio, y fue utilizado para ilustrar un petitorio que realizaron al GCBA en 2015:

era una manera de decir también, nosotros les contestamos, los artistas, los que sumamos a este espacio de resistencia contestamos de esta manera y esta es una forma de comunicarnos nuestra y que no tiene que ver con el distrito, tiene que ver con nuestra historia. O sea, tiene que ver con nuestra identidad. Entonces, ese petitorio fundacional que hicimos lo dividimos en siete ejes, y por cada eje del petitorio hicimos un mural. (Artista plástica y referente de LBRP, entrevista personal, agosto de 2017)

La realización de murales como estrategia de visibilidad se refuerza aún más a partir de la avanzada del GCBA con el programa Color BA en 2017. En julio de ese año LBRP, en colaboración con el colectivo artístico Fileteadores del Conurbano, ${ }^{12}$ decidió "ganar la calle" con una gran convocatoria artístico-social a distintos colectivos o muralistas individuales con temáticas como "Consecuencias de las políticas de exclusión”, "Desaparecidos del barrio de La Boca y presos políticos", "Especulación inmobiliaria y venta de tierras públicas" y "Violencia institucional", entre otros. ${ }^{13}$ Al finalizar, los integrantes de LBRP organizaron una visita guiada por los murales realizados. La importancia del encuentro también fue reconocida institucionalmente al ser declarada de interés cultural por la Legislatura de la Ciudad, lo que da cuenta de otros cruces políticos (el Estado, ya se sabe, no es un ente monolítico) que posibilitan cierto apoyo institucional a este tipo de iniciativas populares.

Por último, también es posible observar su distribución geográfica como estrategia. Si bien la mirada principal se enfoca al diálogo con los vecinos de La Boca -interesada en sus problemas cotidianos y con una estética reconocible para ellos- resulta igualmente accesible para los visitantes. De hecho, uno de los murales fue realizado en una de las paredes de un conventillo-vivienda que linda con Caminito con la clara intención de que sea visto por los turistas que pasean por allí. Otros murales situados en la zona semiturística que bordea Caminito también permiten pensar en un destinatario múltiple. Respecto de este punto, la estrategia se apoyó en un código implícito dentro del muralismo: nadie tapa el mural de otro, salvo con permiso del autor. En la puja por la apropiación del espacio, esto significa que, a mural pintado, pared ganada. Así, en el mural, lo simbólico y lo material muestran nuevos cruces en la "defensa del barrio”. Esta estrategia, además, resulta más legítima que otras intervenciones plásticas disruptivas, como las firmas o grafitis dentro del espacio ordenado para el turismo, que son rechazadas por la ciudadanía e incluso por vecinos y comerciantes del barrio (Figuras $5 \mathrm{a}$ y $5 \mathrm{~b}$ ).

Cabe mencionar que este tipo de intervenciones como disrupción del espacio turístico y sus prácticas establecidas no son las únicas. Durante la realización del trabajo de campo en el espacio turístico de Caminito, pude cruzarme con protestas de personas
12. Esta agrupación, que combina el arte mural con el fileteado porteño, realiza trabajos a pedido de organizaciones sociales con temática cultural, social y política por todo el país: https://www. facebook.com/muralesfileteados/

13. Los murales del encuentro pueden verse en la página de Facebook de LBRP: https://bit.ly/2LZhquk 
Figura 5a. Ubicación de murales de LBRP y Color BA. Fuente: Elaboración propia sobre mapa del GCBA.
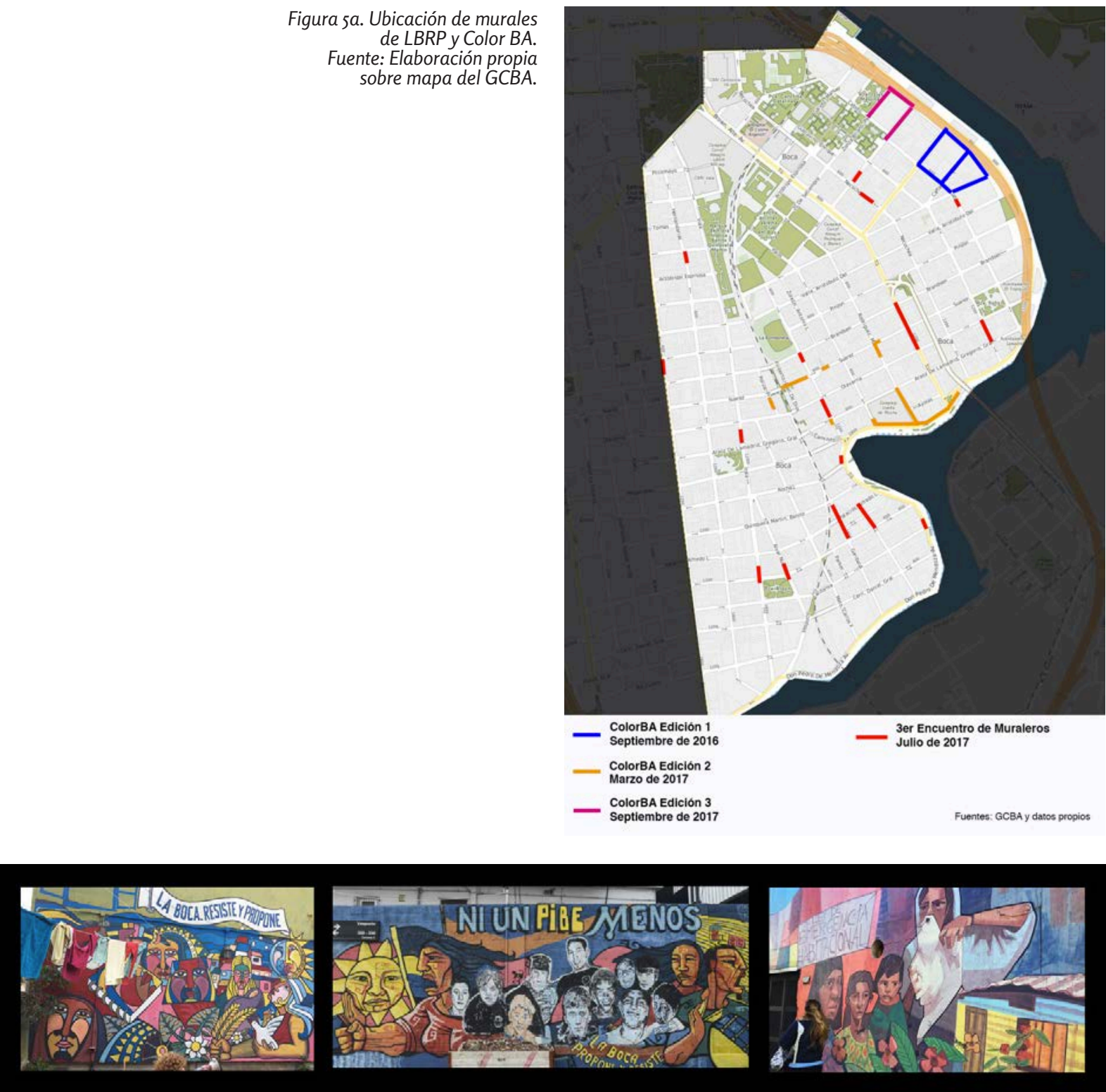

Figura sb. Ejemplo de murales de LBRP.

Fuente: fotos de la autora.

desalojadas, manifestaciones de los trabajadores de la feria artesanal, y hasta un escrache al mismo jefe de Gobierno durante la inauguración del restaurado puente transbordador. En todas estas ocasiones, los vecinos y trabajadores del lugar se esfuerzan por romper la postal y mostrar el "lado B" de los cambios que se están imponiendo en el barrio. En algunos casos, los turistas interrumpen su paseo y atienden a estas demandas preguntando, filmando y sacando fotos. No obstante, en la mayoría de ellos, los visitantes parecen no comprender bien qué es lo que sucede. La cantidad de estímulos que existen dentro del espacio turístico compiten fuertemente por la atención del público. En este contexto, las interrupciones conflictivas tienden a ser ignoradas en pos del momento agradable que se está pasando. Es por ello que resulta relevante destacar a los murales convocados por LBRP como formas de oposición a través del arte. Al remitir a las estrategias de apropiación y resemantización del espacio boquense por parte de las autoridades, su reapropiación por las organizaciones sociales y culturales los transforma en herramienta más efectiva de visibilización y resistencia territorializada. 


\section{Conclusiones. El arte urbano como frontera, entre la imposición y la resistencia}

Este trabajo ha procurado mostrar el lugar político que adquiere el arte urbano en la actualidad y su utilización como estrategia de marcación territorial y simbólica en la disputa por la apropiación de los sentidos asociados a La Boca. De este modo, es posible establecer ciertos recorridos que corren de forma paralela, se cruzan, chocan, se anulan o se ignoran.

En primer lugar, y en línea con lo indicado por Thomasz (2017), se observa que el barrio es comunicado por el GCBA como un lugar "vacío" al que hay que llenar con arte. Esta construcción permite un doble salto: por un lado, evita el diálogo y la confrontación con los usos tradicionales del arte en el barrio, ligados a lo comunitario y lo social. Por otra parte, también se despega de los relatos negativos sobre el barrio que convivían con la mirada pintoresquista y turística. Igualmente, los sentidos anteriores permanecen, por lo que encontramos una coexistencia híbrida y conflictiva de los tres relatos: La Boca pintoresquista para turistas, La Boca abandonada para vecinos y La Boca cool para inversores y nuevos consumidores.

Entonces, ¿qué se muestra y cómo se visibiliza? Volviendo a la metáfora planteada en los subtítulos, "de la boca para afuera", el programa Color BA se enmarca en la construcción de un barrio joven y cool, pero se ve obligado a dialogar con el barrio "tradicional" y con el barrio "peligroso". La domesticación y el disciplinamiento del espacio propuesto por el recorrido de los murales realizados en las cuatro ediciones claramente dan cuenta de las zonas de interés inmobiliario.

Mientras tanto, "de la boca para adentro", algunas organizaciones barriales se nuclearon para resistir la avanzada recualificadora oficial a partir de tomar lo que es propio. Esto implica que, además de realizar reclamos por las vías habituales —manifestaciones en la vía pública, denuncias en los medios de comunicación, acciones judiciales-, también buscan visibilizar su reclamo con manifestaciones artísticas renovadas en el espacio público, es decir, las mismas herramientas con las que el gobierno busca atraer turistas e inversores. Claro que su utilización no es igual.

Para Color BA, los murales sirven para fronterizar un nuevo espacio, al indicar cuáles son los caminos a seguir dentro de un perímetro ampliado pero acotado a la vez. Las visitas guiadas organizadas por el Ente de Turismo del GCBA a los "nuevos murales de La Boca" pueden verse como una suerte de iniciación para aquellos vecinos pioneros que luego correrán la voz de que la Boca no es más un barrio peligroso sino que es muy seguro, que está lleno de arte contemporáneo al aire libre y propuestas modernas como las de la Usina del Arte (epicentro de estas visitas y de los festivales oficiales organizados en el barrio). Se trata de una propuesta estética que no va más allá de la ornamentación del espacio público pero que tiene efectos materiales, ya que promueve la instalación de un nuevo entorno residencial y comercial de mayor poder adquisitivo. ${ }^{14}$

Por el contrario, los murales de LBRP se apoyan en la tradición de arte boquense y fueron expresamente realizados para denunciar la realidad del barrio. Al "ganar" las paredes con arte, el código entre muralistas indica que no se las van a cubrir, con lo cual fronterizan el espacio hacia afuera, y así impiden que avance el programa del GCBA. Al mismo tiempo, la distribución de los murales - desplegados por el barrio enteropermite pensar en la búsqueda de una unidad que recomponga la histórica solidaridad vecinal del barrio, para desfronterizarlo hacia dentro. Al invitar a los vecinos a realizar los recorridos guiados por aquellas zonas del barrio que les resultan ajenas, se abren
14. En la zona de la Usina del Arte esto puede apreciarse a partir de la realización de Puerto Pampa (proyecto iniciado en 2013 y cuya primera etapa se inauguró en 2014), un emprendimiento inmobiliario de lujo que refuncionaliza el exfrigorífico Pampa. Además, el GCBA está gestionando la venta de terrenos públicos para realizar torres de vivienda suntuaria frente al complejo Catalinas, lo que es fuertemente resistido por los vecinos. Para más información: https://bit. ly/2XfsGec; https://bit.ly/2Ki8QZz 
más posibilidades de verse como iguales, y así entender que el enfrentamiento no debe ser entre ellos sino con la avanzada renovadora.

Para finalizar, es necesario aclarar que el proceso que he descrito aquí no está acabado. Las vinculaciones del arte urbano con el territorio son conflictivas y contradictorias. De acuerdo con el análisis presentado, el gobierno encuentra en esta expresión artística una herramienta de disciplinamiento y domesticación del espacio urbano — degradado, peligroso, o simplemente anónimo - que resulta barata, rentable y de alto impacto en la opinión pública. Con menos recursos económicos pero con una gran organización territorial, los colectivos sociales y culturales que lo enfrentan apelan a toda su fuerza e imaginación para visibilizar los impactos negativos de los cambios en el barrio. En una puja que avanza pared a pared, habrá que ver cuál es la efectividad de estas marcas urbanas efímeras en un contexto de cambios materiales más profundos.

\section{Financiamiento:}

Este trabajo presenta resultados de una investigación llevada a cabo en el marco del proyecto de investigación PICT 2015-1160 “El patrimonio urbano en cuestión: tensiones y negociaciones en torno a su instrumentalización de cara al turismo. Buenos Aires 2007-2015". "Este documento es resultado del financiamiento otorgado por el Estado Nacional, por lo tanto queda sujeto al cumplimiento de la Ley No 26.899”. Organismo que ha financiado: Agencia Nacional de Promoción Científica y Técnica, Argentina.

\section{Sobre la autora}

Doctora en Ciencias Sociales y licenciada en Sociología por la Universidad de Buenos Aires. Especialista en Gestión Cultural por la Universidad de San Martín. Magíster en Historia y Cultura de la Arquitectura y la Ciudad por la Universidad Torcuato Di Tella. Investigadora asistente CONICET. Docente de posgrado en la Facultad de Arquitectura, Diseño y Urbanismo y en la Facultad de Ciencias Sociales de la Universidad de Buenos Aires. 


\section{Q Referencias bibliográficas}

»Amendola, G. (2000). La ciudad postmoderna. Montevideo: Celeste.

» Belej, C. (2014). 'Una exposición permanente'. Políticas de la imagen en los edificios públicos a través de sus murales en la década de 1930. Travesía, 16, 29-50. Recuperado de http://www.travesia-unt.org.ar/pdf/numero16/ceciliabelej.pdf.

"Carman, M. (2006). Las trampas de la cultura. Los "intrusos” y los nuevos usos del barrio de Gardel. Buenos Aires: Paidós.

» Fabarón, A. C. (2013). Prácticas de imagen, prácticas espacio-temporales e identificaciones sociales. Una etnografía del barrio de La Boca (tesis de doctorado). Instituto de Altos Estudios Sociales, Universidad de San Martín, Buenos Aires, Argentina.

» Goicoechea, M. E. (2017). Renovación urbana en el sur porteño y el 'éxito' del Distrito Tecnológico. Algunas claves para comprender el dinamismo inmobiliario. Quid 16, 7, 3061. Recuperado de https://bit.ly/2/8jDGZ

» Gómez Schettini, M. y Zunino Singh, D. (2008). La (re)valorización de la zona sur y su patrimonio histórico-cultural como recurso turístico. En H. Herzer (Ed.), Con el corazón mirando al Sur. Transformaciones en el sur de la ciudad de Buenos Aires (pp.325-367). Buenos Aires: Espacio.

» González Bracco, M. y Kotschack, L. (2017). El espacio turístico, entre el enclave y el derrame: estudio en dos barrios de Buenos Aires. Cuadernos de Geografía: Revista Colombiana de Geografía, 26(2), 373-397. Recuperado de https://bit.ly/2vAvlsn

» Gorelik, A. (2004). La grilla y el parque. Espacio público y cultura urbana en Buenos Aires 1887-1936. Bernal: Universidad Nacional de Quilmes.

» Guevara, T. (2011). ¿La ciudad para quién? Políticas habitacionales y renovación urbana en La Boca. Cuaderno Urbano, 11(11), 81-99.

» Gutman, M. y Hardoy, J. E. (2007). Buenos Aires 1536-2006. Historia urbana del área metropolitana. Buenos Aires: Infinito.

»Hernández, S. (2017). El rol del Centro Metropolitano de Diseño en el proceso de patrimonialización de Barracas (Ciudad de Buenos Aires). Quid 16, 7, 94-119. Disponible en https://bit.ly/2yb4Kgq

»Kozak, C. (2004). Contra la pared. Sobre graffitis, pintadas y otras intervenciones urbanas. Buenos Aires: Libros del Rojas.

» Lacarrieu, M. (1993). Luchas por la apropiación del espacio y políticas de vivienda: el caso de los conventillos de La Boca (tesis de doctorado). Facultad de Filosofía y Letras, Universidad de Buenos Aires, Buenos Aires, Argentina.

» Mignaqui, I., Szajnberg, D. y Ciccolella, P. (2005). Clusters creativos en la Ciudad de Buenos Aires: estudios de cine y televisión, moda y diseño en 'Palermo Hollywood' y 'Palermo Soho'. Ponencia presentada en 41st ISOCARP Congress, Bilbao.

» Muñoz, A. (1966). Vida de Quinquela Martín. Buenos Aires: Edición de autor.

» Murillo, S. (2013). El paradigma de la ciudad empresa. En J. Marín (Comp.). La ciudad empresa (pp.25-43). Buenos Aires: Ediciones del Centro Cultural de la Cooperación.

» Novoa, G. (2005). Puerto Madero: un proyecto bisagra. En M. Welch Guerra (Ed.), Buenos Aires a la deriva. Transformaciones urbanas recientes (pp. 203-233). Buenos Aires: Biblos. 
"Roitman, A. (2017). Articulaciones entre las instancias de la planificación urbana y su implementación en la ciudad de Buenos Aires: el Plan Maestro Comuna 8: lo legal y lo legítimo. Ponencia presentada en el IX Seminario Internacional de Investigación en Urbanismo, Barcelona-Bogotá.

» Schacter, R. (2014). The ugly truth: Street Art, Graffiti and the Creative City. En Art \& the Public Sphere, 3(2), 161-176. DOI: 10.1386/aps.3.2.161_1

» Schacter, R. (2016). Graffiti and street art as ornament. En J. I. Ross (Edit.), Routledge Handbook of Graffiti and Street Art (pp.141-157). Londres: Routledge.

»Socoloff, I. (2013). Polos, distritos y enclaves en Buenos Aires. De la pedagogía del inversor a la 'inflación' de los precios del suelo. En J. Marín (Comp.), La ciudad empresa. (pp. 67-88). Buenos Aires: Ediciones del Centro Cultural de la Cooperación.

»Szajnberg, D. (2010). Torres amuralladas. Buenos Aires: Nobuko.

» Thomasz, A. G. (2012). De establecidos y outsiders en el centro histórico de la Ciudad de Buenos Aires. Papeles de Trabajo - Centro de Estudios Interdisciplinarios en Etnolingüística y Antropología Socio-Cultural, 24, s/p. Recuperado de http://rephip.unr.edu.ar/ handle/2133/2221

»Thomasz, A.G. (2017). Etnografía de un proceso de resemantización simbólico: del barrio de La Boca a Distrito de las Artes. Quid 16, 7, 67-93. Recuperado de https://bit. ly/2LGkGJJ

»Zarlenga, M. y Marcús, J. (2014). La cultura como estrategia de transformación urbana. Un análisis crítico de los casos de Barcelona y Buenos Aires. En M. Margulis, M. Urresti y H. Lewin (Eds.), Intervenir en la cultura. Más allá de las políticas culturales. (pp.33-55). Buenos Aires: Biblos. 